\title{
A LITERATURA BRASILEIRA EM TRADUÇÃO: O PROGRAMA DE APOIO À TRADUÇÃO E À PUBLICAÇÃO DE AUTORES BRASILEIROS NO EXTERIOR COMO FERRAMENTA DE INTERFERÊNCIA NO POLISSISTEMA LITERÁRIO
}

\section{BRAZILIAN LITERATURE IN TRANSLATION: THE SUPPORT PROGRAM FOR THE TRANSLATION AND PUBLICATION OF BRAZILIAN AUTHORS ABROAD AS AN INTERFERENCE TOOL IN THE LITERARY POLYSYSTEM}

Lilia Baranski Feres UniRitter - Centro Universitário Ritter dos Reis Porto Alegre, Rio Grande do Sul, Brasil

Valéria Silveira Brisolara Pontifícia Universidade Católica do Rio Grande do Sul Porto Alegre, Rio Grande do Sul, Brasil

RESUMO: O baixo consumo de literatura brasileira no mercado internacional expressa sua dita posição periférica no polissistema literário e justifica os investimentos do Programa de Apoio à Tradução e à Publicação de Autores Brasileiros no Exterior. Iniciativa federal para incrementar a disseminação da cultura e literatura brasileiras no exterior, o programa concede aporte financeiro a editoras estrangeiras interessadas em traduzir e publicar obras brasileiras. Por se tratar de um importante incentivo, cuja agenda prevê significativos investimentos até 2020, torna-se relevante investigar os resultados atingidos pelo programa e refletir acerca de seus (possíveis) desdobramentos. Para isso, são avaliados dados quantitativos referentes ao período 2010-2015, com o intuito de averiguar o número de obras sendo traduzidas e publicadas no exterior e os países responsáveis por essas traduções. Os dados podem nos fornecer importantes informações a respeito da posição do Brasil no polissistema literário, bem como de sua interação com os demais países.

PALAVRAS-CHAVE: Literatura brasileira; Tradução; Programa de Apoio à Tradução e à Publicação de Autores Brasileiros no Exterior; Polissistema 
ABSTRACT: The little consumption of Brazilian literature worldwide expresses its marginal position in the literary polysystem and justifies the investments of the Support Program for the Translation of Brazilian Authors Abroad. A federal initiative to increase Brazilian literature and culture dissemination abroad, the program provides financial support to foreign publishing houses interested in translating and publishing Brazilian works. As it is an important initiative, whose agenda plans investments until 2020, it is necessary to investigate the results achieved by this program and to discuss its (possible) outcomes. In order to do so, quantitative data from the 2010-2015 period are analyzed with the intention of investigating the number of titles being translated and published abroad, as well as the countries responsible for these translations. This data can provided us with important information regarding the position of Brazil in the literary polysystem as well as its interaction with other nations.

KEYWORDS: Brazilian literature; Translation; The Support Program for the Translation of Brazilian Authors Abroad; Polysystem 


\section{INTRODUÇÃO}

A tradução caracteriza-se por ser uma atividade transcultural. Nesse fluxo contínuo e cada vez mais intenso, a tradução também se apresenta como prática social de alta responsabilidade. Ao passo que somente a tradução pode nos oferecer acesso a determinados discursos (ideias, culturas), esses mesmos discursos são sempre mediados por um tradutor, parte subjetiva e também constituída socialmente desse processo. A tradução pode tanto fomentar o desenvolvimento de uma literatura e de uma sociedade, de estabelecer novas ideias, novos gêneros, novos padrões, de edificar o poder de uma cultura sobre outra, quanto minimizar inovações, alterar e omitir informações. A relevância da atividade tradutória no intercâmbio de pessoas, produtos e ideias fica ainda mais evidente quando percebemos que a criação e a circulação de discursos que fundamentam a compreensão de identidades passam, incontáveis vezes, pelas mãos de um tradutor. Assim, literatura - enquanto manifestação da diversidade cultural -, cultura e identidade mantêm relações muito estreitas com a tradução.

Mesmo o português sendo a sexta língua com o maior número de falantes do mundo, a literatura de língua portuguesa está muito longe de estar entre as mais traduzidas. Esse desequilíbrio pode ser visto tanto como resultado quanto justificativa para a interferência que línguas e culturas de países ditos periféricos sofrem daqueles ditos centrais. Países não hegemônicos entram em uma disputa desigual com os hegemônicos, que se materializa na representatividade de sua literatura, de sua cultura; enfim, de seu poder econômico. De acordo com um estudo encomendado para o relatório mundial da UNESCO acerca de diversidade cultural (2009), 75\% do total de livros cadastrados na plataforma Index Translationum $^{1}$ (1979-2007), base de dados da UNESCO com informações bibliográficas de livros traduzidos e publicados nos países membros, foram vertidos de apenas três línguas: inglês, francês e alemão. Embora a plataforma possa ser considerada problemática, principalmente pela falta de atualização, já que depende de informações enviadas pelas editoras, que nem sempre o fazem, seus dados permitem, com temperança, ponderações sobre as trocas interculturais propiciadas pela tradução. Com relação à língua de partida das obras traduzidas, $o$ inglês sozinho é responsável por 55\% dos livros traduzidos em todos os gêneros. Outra estatística reveladora, no que diz respeito à assimetria desse tipo de troca cultural, é que das cerca de 800 línguas identificadas no Index, vinte (sendo dezesseis delas línguas europeias) constituem-se como língua de partida de $96 \%$ dos livros traduzidos. Similar disparidade pode ser percebida no tocante às línguas de chegada: $50 \%$ dos livros registrados foram traduzidos para somente cinco idiomas: alemão, espanhol, francês, inglês e japonês (BRISSET, 2011).

Em consulta ao Index Translationum (realizada em 17/02/2017) é possível constatar que o português é língua de partida em $0,5 \%$ dos livros cadastrados (apenas para efeito de comparação, o inglês é língua de partida em $54,7 \%$ dos livros). Essa desproporção nos valores não é surpresa, pois se sabe que a literatura

\footnotetext{
${ }^{1}$ Disponível em: <www.unesco.org/culture/xtrans/>. Acesso em: 17 fev. 2017.
} 
de língua portuguesa, sobretudo a brasileira contemporânea, é pouco lida e (muito) pouco traduzida no exterior (OLIVEIRA, 2004). Nessa relação de trocas interculturais, tanto a língua portuguesa quanto a literatura de língua portuguesa ocupam uma posição periférica, o que faz com que, lamentavelmente, pouco se traduza da nossa literatura e da literatura de língua portuguesa.

É por conta de problemáticas dessa ordem (entre tantas outras, evidentemente) que se torna crucial explorar questões de tradução sob outra ótica. $\mathrm{O}$ processo tradutório sempre foi e nunca deixará de ser complexo, mas antigamente grande parte dessa complexidade era ignorada, ora por ser desconhecida, ora por ser negligenciada intencionalmente. Hoje, porém, é imperativo que a tradução seja abordada como o fenômeno intricado que é, exigindo olhares atentos às relações estabelecidas entre os diferentes sistemas constituidores dos grandes sistemas literário e cultural, considerando, portanto, fatores sociológicos, políticos e ideológicos que atuam em tempo e espaço específicos. É nesse contexto que, em 2011, é retomada uma política de internacionalização do livro brasileiro que visa à maior presença no exterior da produção nacional científica e cultural editada. Originalmente criado em 1984, o então chamado Programa de Apoio à Tradução de Livros Brasileiros no Exterior estreou com o apoio da Fundação Vitae ${ }^{2}$, que a partir de 1990 ficou sob a esfera do Departamento Nacional do Livro, vinculado à Fundação Biblioteca Nacional (FBN) e à Coordenadoria Geral de Livro e Leitura (CGLL) (AJALA, 2013; MARTINS 2008), ambas instituições responsáveis pela realização das ações desenvolvidas pelo Ministério da Cultura (MinC) e pelo Ministério da Educação (MEC) dentro do Plano Nacional do Livro e Leitura (PNLL).

Considerando o exposto, o objetivo deste artigo é investigar os resultados atingidos pelo Programa de Apoio à Tradução e à Publicação de Autores Brasileiros no Exterior e refletir acerca de seus (possíveis) desdobramentos. A fim de alcançar esse propósito, são avaliados os dados quantitativos referentes ao período 2010-2015 obtidos junto à Fundação Biblioteca Nacional através de pedido de acesso à informação no Portal da Transparência - plataforma e-SIC (Sistema Eletrônico de Informação ao Cidadão). Acredita-se que a análise dos dados pode nos fornecer importantes informações a respeito da posição do Brasil no polissistema literário e sua interação com os demais países assim como salientar a importância de programas como o mencionado.

\footnotetext{
${ }^{2}$ A Fundação Vitae foi uma associação civil sem fins lucrativos que surgiu no Brasil no início da década de 1980 e seguiu atuante até 2005. Um de seus principais objetivos foi o incentivo às Artes e à Cultura, através de financiamento a programas, projetos e bolsas de trabalho e de pesquisa (ALMEIDA \& HERENCIA, 2012).
} 


\section{INICIATIVAS GOVERNAMENTAIS ENQUANTO INTERFERÊNCIAS LITERÁRIAS}

Consistindo em uma agenda governamental cujo próprio nome explicita seu objetivo primordial, com planos de investimentos da ordem de $\mathrm{R} \$ 76$ milhões até 2020, a política é desmembrada em diversos programas, entre os quais: o Programa de Apoio à Publicação de Autores Brasileiros na Comunidade dos Países de Língua Portuguesa (CPLP), que consiste em bolsas para editoras dos países-membro da CPLP, concedidas a interessados em adaptar textos brasileiros para as características do português falado em Portugal, em países africanos onde o português é a língua oficial e no Timor Leste; o Programa de Residência de Tradutores Estrangeiros no Brasil, direcionado a tradutores estrangeiros que estejam trabalhando na tradução de livros brasileiros; o Programa de Intercâmbio de Autores Brasileiros no Exterior, que contempla editoras estrangeiras que promovam a literatura brasileira por meio de palestras, sessões de autógrafos e entrevistas; e o Programa de Apoio à Tradução e à Publicação de Autores Brasileiros no Exterior.

O último programa mencionado, objeto de estudo deste trabalho, tem o intuito de "difundir a cultura e a literatura brasileiras no exterior" através do fornecimento de apoio financeiro a editoras estrangeiras que tenham interesse em traduzir (para qualquer idioma), publicar e distribuir (em forma de livro impresso ou digital), no exterior, obras de escritores brasileiros que tenham sido previamente publicadas em português no Brasil. Em virtude de uma parceria feita com o Conselho Nacional de Desenvolvimento Científico e Tecnológico (CNPq), o programa pode apoiar tanto projetos de obras técnicas ou científicas nas áreas de Ciências Humanas e Sociais Aplicadas, Ciências da Vida, Engenharias, Ciências Exatas e da Terra quanto no campo da literatura, em especial os gêneros romance, conto, poesia, crônica, infantil e/ou juvenil, teatro, obra de referência, ensaio literário, ensaio de ciências sociais, ensaio histórico, ensaio de vulgarização científica e antologias de poemas e contos, integrais ou em parte. O auxílio pode ser concedido a propostas de traduções inéditas, novas traduções ou reedições de obras já traduzidas no país e que tenham se esgotado ou estejam fora de mercado por no mínimo três anos.

Outro caminho que o Ministério da Cultura encontrou para intensificar a presença do Brasil no exterior foi através de maior participação de editoras nacionais em eventos literários internacionais. A Fundação Biblioteca Nacional investiu na elaboração de uma agenda, que também se estende até 2020, de inserção de nosso país em uma série de eventos: Feira do Livro de Frankfurt (país homenageado), em 1994 e 2013; Bienal Internacional do Livro do Rio de Janeiro, em 2011; Feira do Livro de Bogotá (convidado de honra), em 2012; Feira do Livro de Bolonha (país homenageado), em 2014; Feira Internacional do Livro de Gotemburgo (convidado de honra), em 2014; Feira do Livro de Caracas (país destaque), em 2014; Salão do Livro de Paris (país convidado), em 2015; Feira do Livro de Londres (país homenageado), em 2016; e Feira do Livro de Nova York 
(país homenageado), em 2017. Todas essas medidas visam a despertar maior interesse das editoras internacionais pela literatura produzida no Brasil.

Falar em internacionalização da literatura brasileira não é tratar somente de tradução. Embora ela seja um importante caminho, da mesma forma precisamos ter em mente que os livros, enquanto produtos literários, assim como outros produtos culturais (filme, música, telas, esculturas, etc.), são bens que ingressam também no ciclo econômico que, por sua vez, dependem de outros elementos. Para Even-Zohar (1990), esse conjunto de elementos corresponderia ao polissistema constituído por instituição, mercado, repertório e outros componentes, todos interligados entre si e, por isso, influenciadores uns dos outros, assunto amplamente tratado na sua Teoria dos Polissistemas. Ainda nessa teoria, a respeito da tradução, Even-Zohar afirma que ela não representa apenas uma parte integrante do sistema literário, mas uma peça que desempenha papel protagonista no polissistema sendo um sistema extremamente ativo dentro dele (1990, p. 46).

As indagações basilares dessa teoria circundam a motivação das transferências entre determinados bens e sistemas, no caso aqui em questão, os sistemas nacional e internacional delimitados pelas obras e pelos países selecionados pelo Programa de Apoio à Tradução e à Publicação de Autores Brasileiros no Exterior. Segundo o autor, seria evidente a imposição, pelo polissistema, de limitações e pressões sobre os modos de selecionar, manipular, amplificar e excluir, observados em seus bens reais (EVEN-ZOHAR, 1990). Considerando que certos textos pertencem ao cânone enquanto outros pertencem às margens, criam-se territórios para tensões entre as posições mais centrais e mais periféricas do sistema.

Nesse sentido, embora estejamos investindo mais em ações que difundem a cultura e literatura brasileiras no exterior - como o Programa de Apoio à Tradução, enfocado aqui -, não há como negar que nosso país, representado pelos autores, suas obras e a língua portuguesa, entra nas disputas por centralidade/capital simbólico no campo literário praticamente na condição de azarão. Cada país apresenta as armas de que dispõe. Even-Zohar (1990) considera que há dois pontos cruciais nesse jogo por poder: critérios de seleção das obras a serem traduzidas e a forma como as traduções são conduzidas. Ambas as questões desvelam intricadas relações entre sistemas de partida e de chegada que se materializam também nos ditos originais e em suas traduções e podem contribuir para um maior ou menor reforço de identidade nacional (FERES\&BRISOLARA, 2015).

Interferência proposital numa tentativa de (melhor) recolocação do Brasil no sistema global, o pacote de medidas voltadas ao sistema literário brasileiro pode, na perspectiva teórica de Even-Zohar, ser considerado uma interferência literária do tipo "dependente" (EVEN-ZOHAR, 1990, p. 55-56), já que um novo sistema de publicação e tradução de autores brasileiros passa a ser criado e expandido através de um sistema externo (no caso, o governo federal - através do Ministério da Cultura e da Fundação Biblioteca Nacional) que provê condições necessárias a sua criação e desenvolvimento. Basta saber se as ações estão cumprindo o propósito ao qual se destinam e, se estão, em que medida. 


\section{RESULTADOSQUANTITATIVOS DOPROGRAMA DE APOIO À TRADUÇÃONOPERÍODO 2010-2015}

Através de análise criteriosa dos dados gerados a partir de 2010, observase que, conforme revela o gráfico 1 (Fig. 1), no ano de 2010, Argentina (3 títulos), França (2 títulos) e Itália ( 2 títulos também) foram os países que mais traduziram e publicaram obras brasileiras, embora os números não se mostrem muito expressivos ${ }^{3}$. Somente editoras de 9 países submeteram-se à avaliação ou receberam o auxílio à tradução. É pertinente sublinhar que nenhum país de língua inglesa compõe a lista de 2010. A soma de publicações dos 9 países participantes resulta em apenas 13 livros.

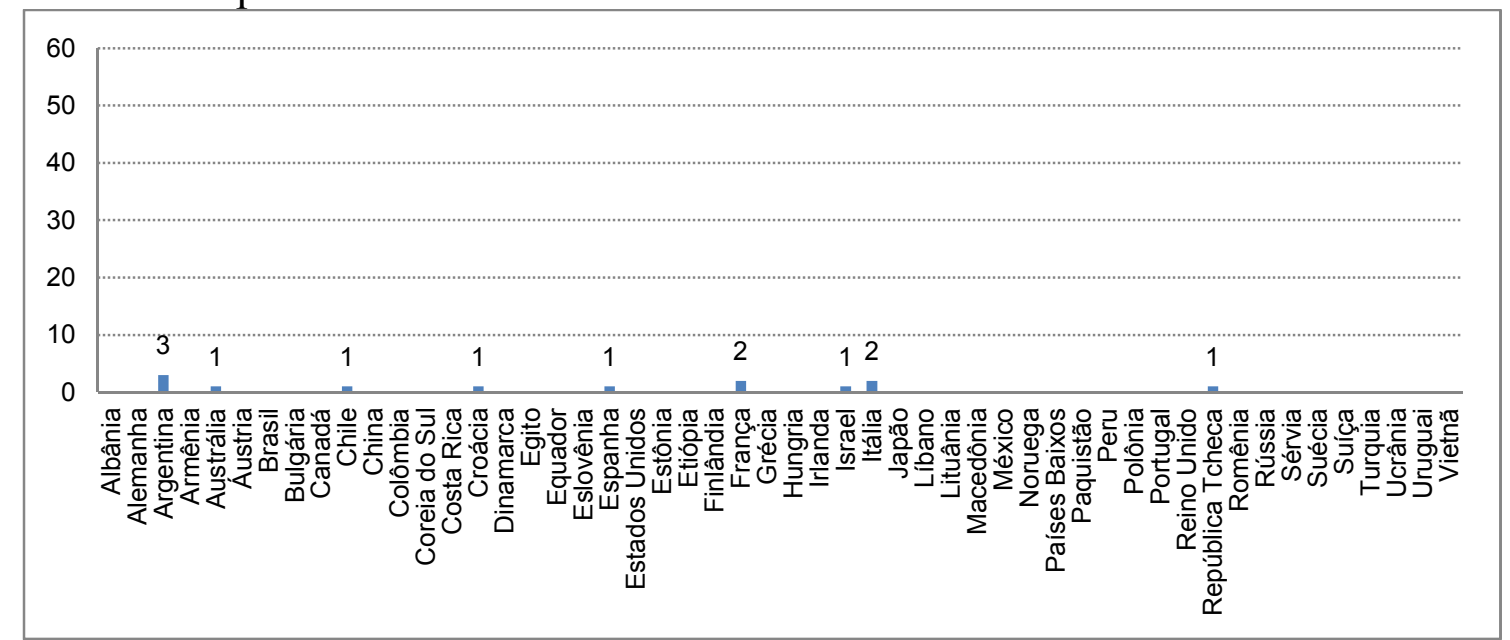

Figura 1: Número de obras traduzidas em $2010^{4}$

No ano de 2011, como mostra o gráfico 2 (Fig. 2), os países que mais traduziram e publicaram títulos brasileiros foram Argentina (8 títulos), Estados Unidos, Espanha e França (4 títulos cada). Apesar do relativo aumento na participação dos Estados Unidos, o Reino Unido ainda não figura na lista de países participantes. É possível que isso se deva ao fato de a nação britânica mostrar-se mais conservadora do que a americana. Independentemente da estreia dos Estados Unidos, da Romênia, dos Países Baixos, dentre outros com menor expressividade, Argentina, França e Itália continuam com relevante atuação no tocante à publicação da nossa literatura. Embora os números sejam discretos, já é possível perceber um aumento de países participantes do programa de tradução. Em 2011 foram 12, em comparação aos 9 do ano anterior. Igualmente, nota-se um significativo acréscimo no total de obras: de 13 títulos em 2010 passamos a $31 \mathrm{em}$ 2011, ou seja, um aumento de $138 \%$.

\footnotetext{
${ }^{3}$ Parte das informações quantitativas relativas ao referido programa governamental foram colhidas e exploradas em trabalho anterior (FERES, 2016).

${ }^{4}$ Todos os gráficos apresentados no trabalho foram elaborados pelas autoras.
} 


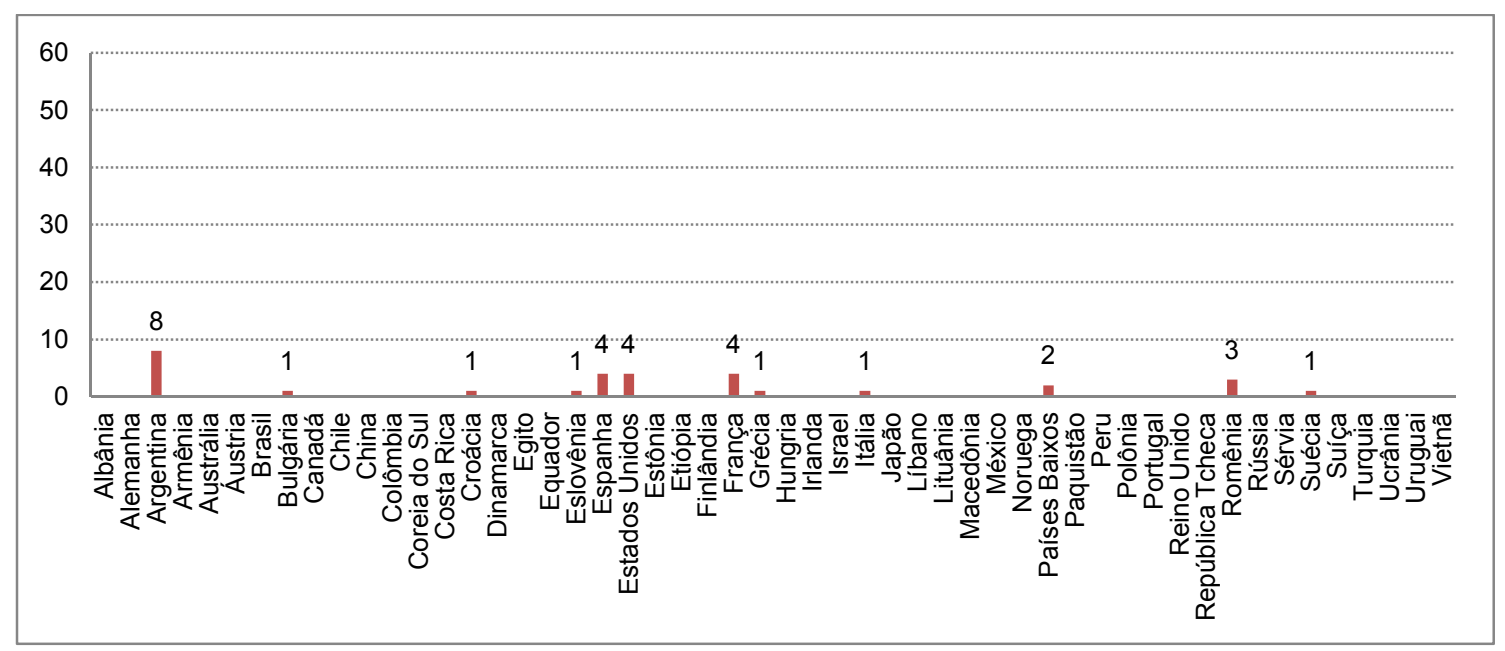

Figura 2: Número de obras traduzidas em 2011

Uma notável mudança acontece em 2012, conforme o gráfico 3 (Fig. 3) revela, quando a quantidade de países participantes dobra. São 24 nações, o que representa um aumento de $50 \%$, cujas editoras receberam apoio à tradução e à publicação de obras brasileiras e uma soma de 79 títulos, configurando um aumento de cerca de $150 \%$. Os países de maior expressividade são Espanha ( 9 títulos, que incluem as publicações em Catalão), Romênia (8 títulos), Brasil (7

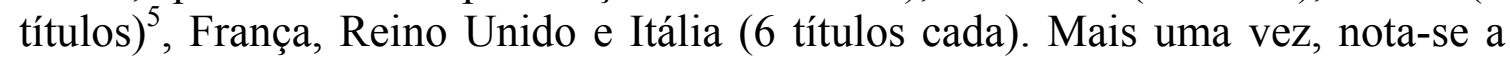
constância de França, Itália, Espanha e Argentina e seus números expressivos. A estreia do Reino Unido (6 títulos), superando os Estados Unidos (4 títulos), pode ter sido fomentada pela atuação vanguardista, em 2011, do país norte-americano que, após publicar obras brasileiras vertidas para a língua inglesa, pode ter facilitado o acesso e o interesse de outros falantes da mesma língua, neste caso o Reino Unido. Também em 2012, observamos a presença inaugural da Alemanha (5 títulos) e de outros países como Irlanda, Peru, Chile, Hungria, México e Sérvia. Portugal também participa (3 títulos), mas a partir do Programa de Apoio à Publicação de Autores Brasileiros na Comunidade dos Países de Língua Portuguesa (CPLP), oferecido a interessados em adaptar obras brasileiras para as particularidades do português de Portugal, de alguns países africanos e do Timor Leste.

\footnotetext{
${ }^{5}$ Tratam-se de obras brasileiras publicadas no Brasil (por editoras estrangeiras) em idioma diferente do português. Foram elas Arquitetura no Brasil, de Hugo Segawa (publicada em inglês); A obscena senhora D, de Hilda Hilst (publicada em inglês); Contos do mar sem fim, de diversos autores (publicada em inglês); História concisa do Brasil, de Boris Fausto (publicada em alemão); Joana a contragosto, de Marcelo Mirisola (publicada em inglês); O outro passo da dança, de Caio Riter (publicado em inglês no formato e-book); e Poemas do céu, de Roseana Murray (publicada em espanhol).
} 


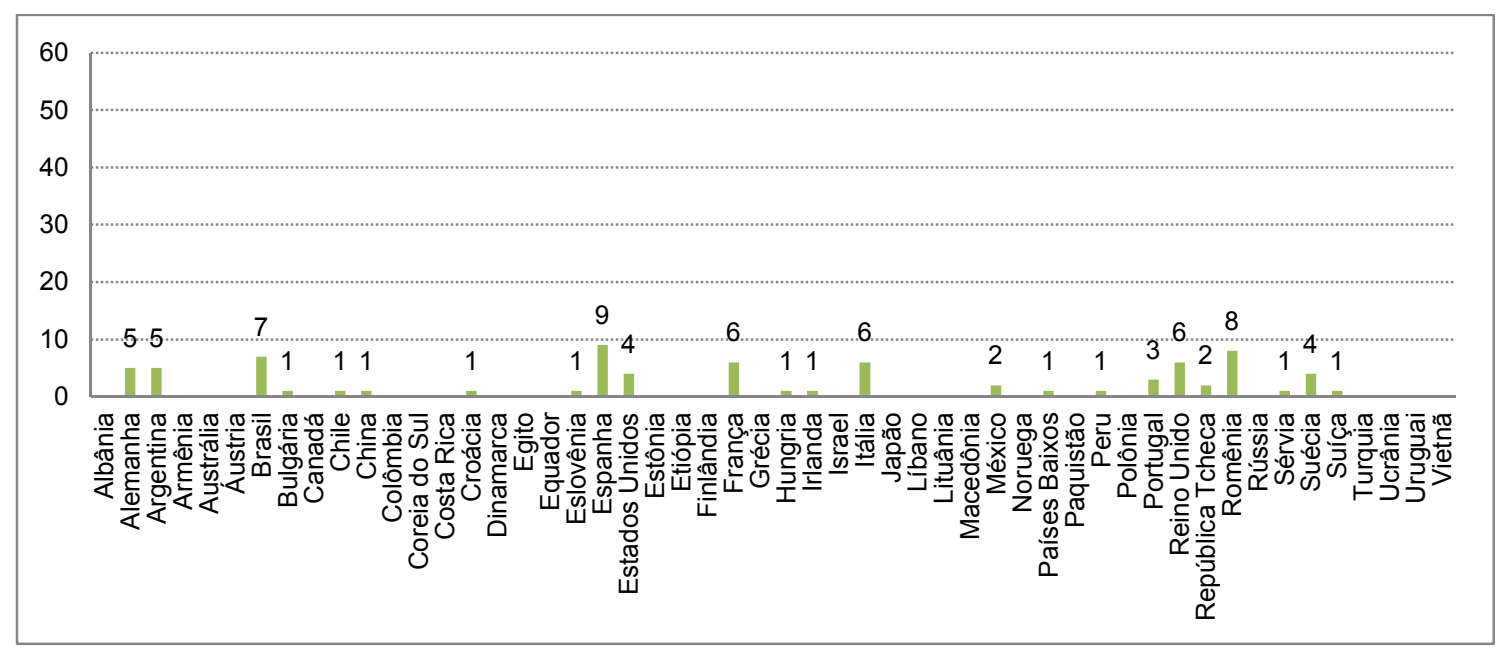

Figura 3: Número de obras traduzidas em 2012

A dita tradição da Alemanha em consumo de literatura brasileira se expressa nos significativos números de 2013, como mostrado no gráfico 4 (Fig. 4). Um total de 59 obras (algumas no formato e-book) em somente um ano, o que representa um aumento de $1.080 \%$ em relação a 2012. Espanha, segundo colocado, publica 18 títulos, deixando patente a distância do primeiro colocado. Dessa vez, Itália (15 títulos), Argentina (15 títulos) e França (12 títulos) perdem a liderança de 2010. Novamente, desconsiderando a discrepante atuação do país germânico, Argentina, Espanha, França e Itália seguem sendo os países que mais publicam nossas obras no escopo aqui delimitado. Os Estados Unidos (10 títulos) voltam a apresentar números mais expressivos do que o Reino Unido (6 títulos) e a Romênia demonstra relativa estabilidade e expressividade no número de publicações. Países como Polônia, Noruega e Líbano aparecem pela primeira vez. Em 2012, constatou-se um ligeiro acréscimo no número de participantes, totalizando 30 países e, evidentemente, em virtude da impactante atuação da Alemanha, o total de obras disparou, chegando a 193, o que configura um aumento de 144\% em relação ao ano anterior. Nota-se que, no ano de 2013, o Brasil foi o país homenageado na Feira do Livro de Frankfurt. É bastante provável que a robusta atuação da Alemanha seja um reflexo do destaque dado ao nosso país no maior evento literário existente. Essa distinção dada ao nosso país pode ser justificada pelos vindouros eventos internacionais de grande porte que sediaríamos: Copa do Mundo 2014 e Jogos Olímpicos 2016. Além disso, o país gozava de maior estabilidade econômica e figurava como promissora aposta para investimentos internacionais. Os resultados de 2013 evidenciam que investimentos para inserção do país nas agendas literárias mundo afora são efetivos e capazes de trazer resultados imediatos bastante representativos. 


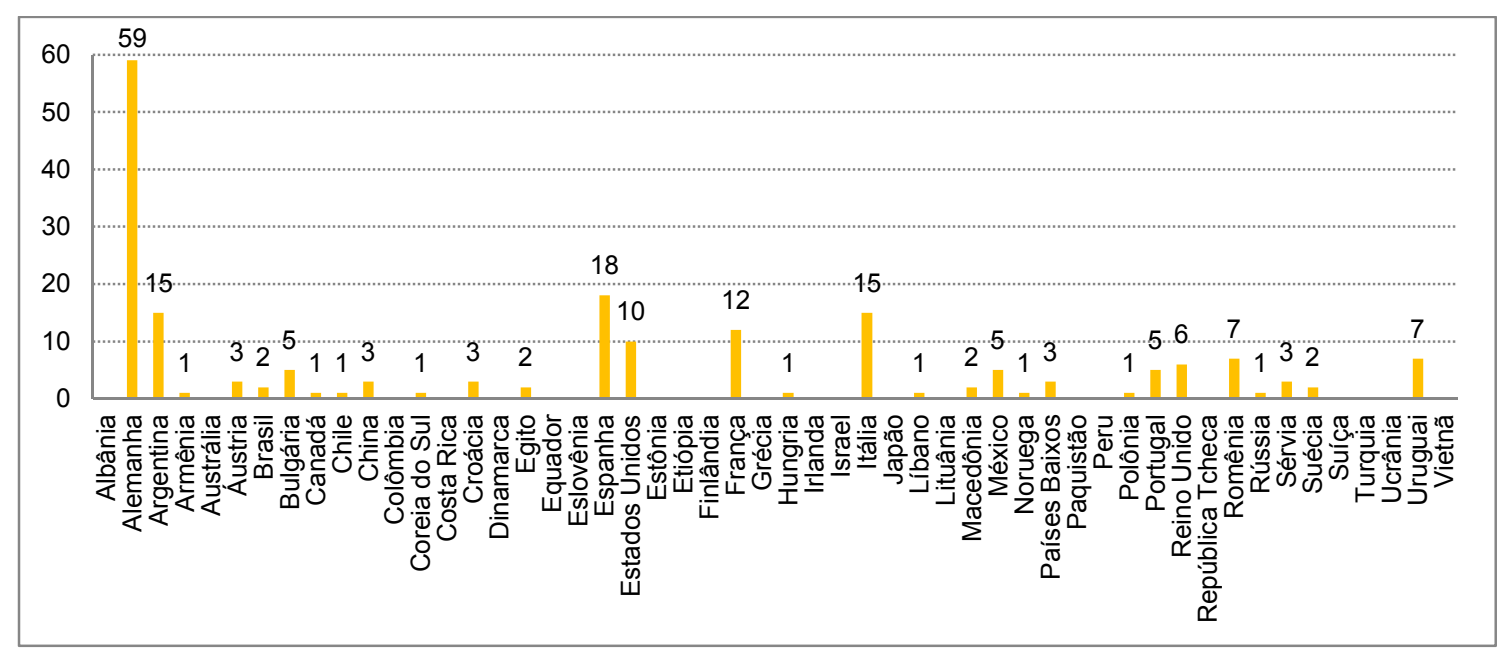

Figura 4: Número de obras traduzidas em 2013

Em 2014, conforme gráfico 5 (Fig. 5), os números caem um pouco, mas somente no que diz respeito à quantidade de livros. Foram 136 obras traduzidas e publicadas em ainda 30 países. No ano em questão, França fica na primeira colocação com 25 títulos (contra 12 do ano anterior). É provável que o país estivesse se preparando para 2015, ano em que o Brasil foi o país destaque na Feira do Livro de Paris, disponibilizando mais obras brasileiras para que o público francês conhecesse um pouco mais da literatura produzida aqui. Em seguida, novamente, vem Espanha e Itália (14 títulos cada). De forma surpreendente, a Alemanha, que ficou em primeiro lugar com seus 59 títulos em 2013, simplesmente não publica nenhuma obra brasileira em 2014, seja porque nenhuma editora germânica se candidatou para as bolsas ou porque nenhuma das que se candidataram teve seu projeto selecionado para receber o incentivo. Mais uma vez, França, Espanha, Itália se mostram relativamente constantes em seu interesse em traduzir e publicar nossa literatura, e a Argentina perde sua posição para o México (11 títulos). Reino Unido (7 títulos) e Estados Unidos (7 títulos) apresentam resultados semelhantes e relativamente discretos, confirmando o parco interesse de países de língua inglesa em traduzir e publicar obras de autores brasileiros.

Esses dados corroboram a teoria de Venuti (1995) de que editoras americanas e inglesas investem suas participações em feiras literárias mais em vendas de direitos autorais de obras de língua inglesa, sobretudo best-sellers, do que em aquisição de direitos autorais de títulos estrangeiros. De acordo com Venuti, o mercado americano "raramente compra os direitos para publicar traduções em língua inglesa de livros estrangeiros" (VENUTI, 1995, p. 14). Os dados aqui apresentados indicam que esses países realmente têm pouco interesse em consumir a literatura brasileira, mesmo com concessão de subsídios.

Ainda, Vietnã e Paquistão participam pela primeira vez. A Suécia, mesmo não apresentando elevados índices, mais que triplicou sua participação em comparação com 2013. Novamente, assim como aconteceu com a Alemanha (depois de receber o Brasil como país homenageado da Feira de Frankfurt de 2013), é provável que esse aumento tenha sofrido influência da presença do Brasil 
como país destaque na Feira Internacional de Gotemburgo em 2014, sugerindo que ações intencionais parecem cumprir seu papel, mesmo de forma modesta.

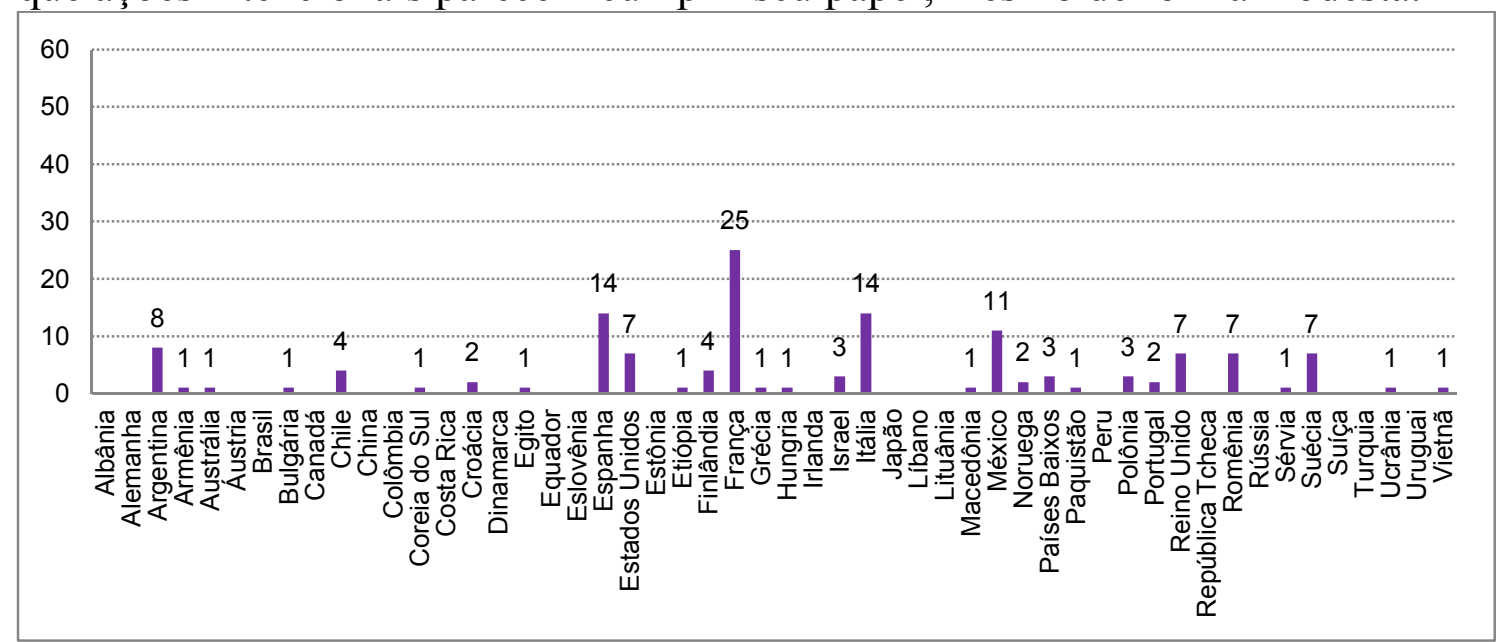

Figura 5: Número de obras traduzidas em 2014

No ano de 2015, como é possível observar no gráfico 6 (Fig. 6), vemos um crescimento oposto ao de 2014. Dessa vez, foi somente o número de países que inflou quase $17 \%$ em relação ao ano anterior. Já no número de livros, 2015 acrescentou somente 1 à lista de obras traduzidas e publicadas por editoras estrangeiras via Programa de Apoio à Tradução, subindo de 136 (em 2014) para 137 (em 2015).

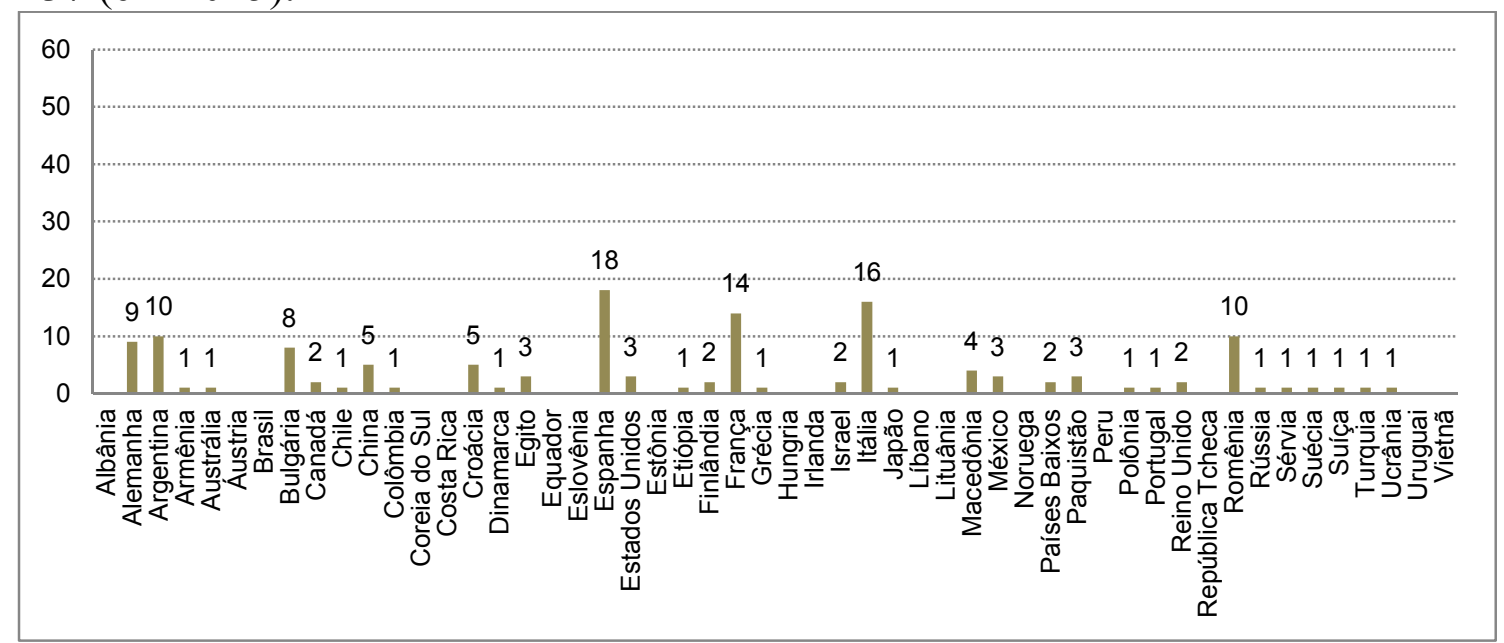

Figura 6: Número de obras traduzidas em 2015

A fim de facilitar a visualização do somatório de obras e países envolvidos no período analisado, o gráfico 7 (Fig. 7) resume o número total de obras traduzidas e publicadas por cada país, inclusive aqueles que lançaram somente um título ao longo dos seis anos estudados. 


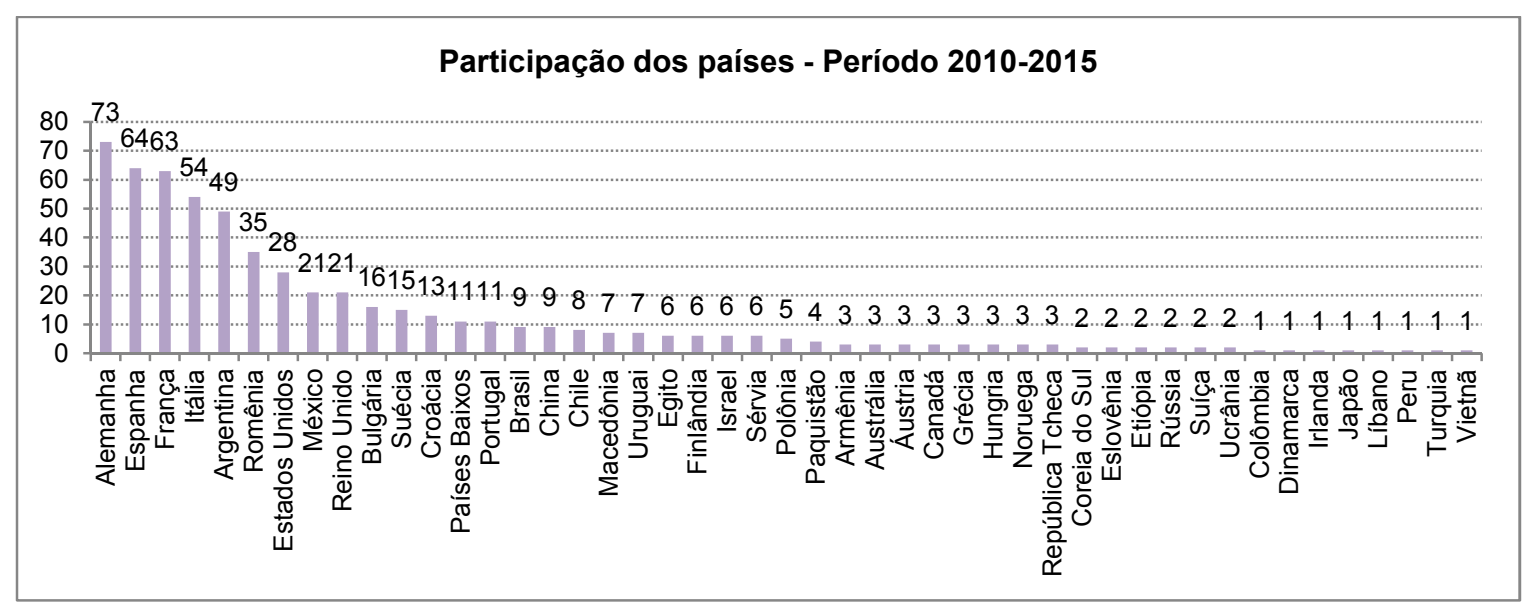

Figura 7: Número total de obras traduzidas no período 2010-2015

A Alemanha lidera devido à sua expressiva atuação em 2013 (59 títulos). Espanha, França, Itália e Argentina aparecem logo em seguida manifestando sua constância e representatividade ao longo do período aqui em foco. Nota-se que países hegemônicos de língua inglesa, Estados Unidos e Reino Unido, mostramse menos significativos, o que poderia ser tomado como menor interesse em adquirir direitos autorais de títulos brasileiros para traduzi-los, reiterando EvenZohar (1990), que sustenta que países detentores de uma literatura nacional forte e bem consolidada tendem a ter na atividade tradutória um papel mais marginal, como é o caso desses dois países. Os dados ainda parecem indicar que medidas de grande porte e alcance como o Programa de Apoio à Tradução e à Publicação de Autores Brasileiros no Exterior não são capazes de exercer interferências representativas no sistema literário anglo-americano a ponto de realocá-lo em uma posição menos central. Entretanto, esses mesmos resultados sugerem que medidas desse tipo podem auxiliar na recolocação do Brasil em uma posição menos marginal.

A evolução ano a ano do número de obras brasileiras traduzidas no exterior com auxílio de verba federal (Fig. 8) nos mostra que a participação do Brasil no cenário literário mundial teve um aumento no período analisado.

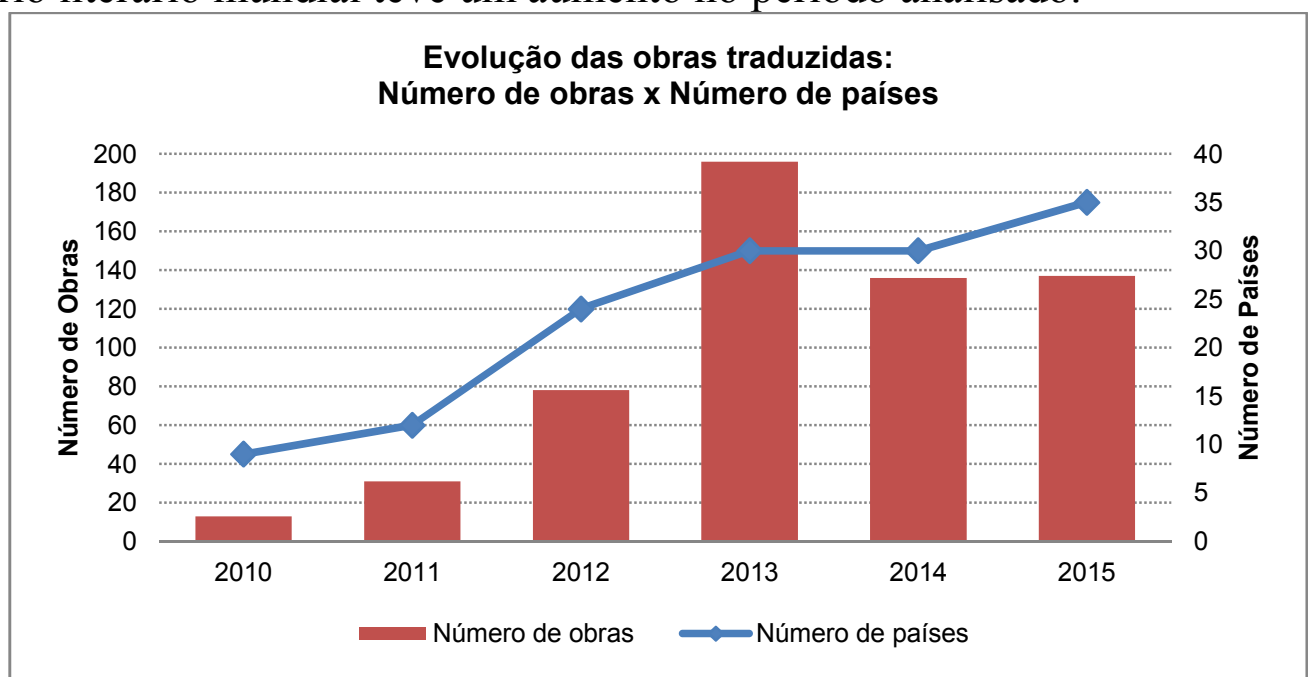

Figura 8: Evolução ano a ano do total de obras traduzidas no período 2010-2015 


\section{CONSIDERAÇÕES FINAIS}

Embora os dados apresentados sejam bastante significativos e nos revelem pistas sobre as relações que se estabelecem entre países/culturas de partida e de chegada, bem como sobre a dinâmica literária global, é importante ressaltar que as informações representadas pelos gráficos referem-se somente às obras publicadas e traduzidas por intermédio do Programa de Apoio à Tradução e à Publicação de Autores Brasileiros no Exterior em um período delimitado (20102015) e, por isso, não podem ser tomadas como representativas do cenário literário e/ou editorial como um todo. Sem dúvida, há inúmeros outros fatores políticos, econômicos e sociais - que ajudam a explicar os resultados encontrados e que não foram profundamente abordados aqui. Tanto dados qualitativos (nome das obras, autores, editoras, tradutores) quanto aspectos socioeconômicos e políticos que compõem o complexo polissistema desses bens culturais são foco de pesquisas ainda em fase de conclusão que serão apresentadas futuramente. Os dados estritamente quantitativos são o primeiro e um importante passo de nossas pesquisas que já nos oferecem uma visão geral e imprescindível para análises vindouras.

No que concerne aos resultados estatísticos encontrados, conclui-se que as iniciativas do governo federal podem configurar-se em ferramentas relevantes para atrair mais atenção para aquilo que é produzido literariamente no Brasil. Os dados sugerem que nosso país tem caminhado em direção a um maior reconhecimento internacional de seus escritores e de sua literatura. Esse assunto, no entanto, não pode ser abordado com ingenuidade. É fato que somente medidas governamentais são insuficientes para equalizar a disparidade existente no intercâmbio de bens culturais entre países centrais e periféricos (EVEN-ZOHAR, 1990). Há muitos outros fatores presentes nessas dinâmicas do sistema literário, que regem o estabelecimento de padrões hegemônicos e que fogem do alcance de medidas desse tipo. De qualquer forma, os resultados encontrados corroboram a importância de se investir em iniciativas de disseminação e de internacionalização da literatura brasileira, seja através da concessão de bolsas de apoio ou da inserção do país nas agendas culturais internacionais. Ainda que esses investimentos pareçam não estar mudando definitivamente o cenário literário mundial, grandes mudanças só podem ser alcançadas se o primeiro passo for dado.

Para fins deste estudo, a análise dos resultados referentes ao Programa de Apoio à Tradução e à Publicação de Autores Brasileiros no Exterior limitou-se aos dados quantitativos, pois a intenção era investigar se essa medida proposta pelo governo federal foi de fato eficaz no sentido de aumentar a oferta de literatura brasileira no exterior. Por isso, apenas o total de livros traduzidos no período delimitado serviu como base para as análises. No entanto, é de igual relevância analisar quais títulos estão sendo importados, quais são as editoras participantes, que autores estão despertando o interesse internacional nesse escopo, entre outros aspectos afins. Afinal, conforme postulado por Venuti, em sua obra Escândalos da tradução (2002), toda tradução gera consequências. 


\section{REFERÊNCIAS}

AJALA, F. M. F. Menino de engenho (José Lins do Rego) na França: um estudo descritivo-comparativo de duas traduções. João Pessoa, 2013. 69 f. Monografia (Bacharelado em Tradução) - Centro de Ciências Humanas, Letras e Artes, Universidade Federal da Paraíba. Acesso em 29 ago. 2017. Disponível em: $<$ http://www.cchla.ufpb.br/ctrad/wp-content/uploads/2014/08/TCC-Flora-MarinaVFinal.pdf $>$.

ALMEIDA, G. S. B; HERENCIA, J. L. A Fundação Vitae e seu legado para a cultura brasileira Parte I: Fontes conceituais, linhas diretivas, programas próprios e legados. Artigo apresentado no III Seminário Internacional de Políticas Culturais ocorrido em setembro de 2012. Acesso em 29 ago 2017. Disponível em: $<$ http://culturadigital.br/politicaculturalcasaderuibarbosa/files/2012/09/Gabriela$\underline{\text { Sandes-Borges-de-Almeida-et-alii.pdf }>\text {. }}$

BRISSET, A. Cultural perspectives on translation. Tradução Marcos Bagno. International Social Science Journal, UNESCO, mar. 2010, v. 61, n. 199, p. 6981, out. 2011.

EVEN-ZOHAR, I. Polysystem studies. Poetics Today. Durham: Duke University Press, v. 11, n. 1, 1990.

FERES; BRISOLARA. Tradução: uma ação política de reforço da identidade nacional. Linguagem em foco. Fortaleza: EUCE, v. 7, n. 1, p. 57-67, 2015.

FERES. A cultura traduzida e a cultura em tradução: a literatura brasileira contemporânea na revista Granta. 2016. 144 f. Dissertação (Mestrado) - Centro Universitário Ritter dos Reis, Programa de Pós-Graduação em Letras, Porto Alegre, 2016.

UNESCO. Index Translationum: World bibliography of translation. Disponível em: <http://www.unesco.org/culture/xtrans/>. Acesso em: 19 fev. 2017.

FUNDAÇÃO BIBLIOTECA NACIONAL. [s.d.]. Carta de serviços ao cidadão. Disponível em: $<$ http://www.bn.br/sites/default/files/documentos/diversos/2014 /1115-institucional/institucional-786.pdf $>$. Acesso em 06 ago. 2015.

MARTINS, M. A. P. "O papel da patronagem na difusão da literatura brasileira: o Programa de Apoio à Tradução da Biblioteca Nacional". In: GUERINI, A.; TORRES, M.H.C.; COSTA, W.C. (Org.) Literatura Traduzida \& Literatura Nacional. Rio de Janeiro: 7Letras, 2008, p. 39-52. Disponível em: $<$ http://150.164.100.248/profs/romulo/data1/arquivos/Literaturatraduzidaeliteratur anacional2008.pdf $>$. Acesso em 29 ago. 2017.

MINISTÉRIO DA CULTURA. 15 jun. 2015. Lançado edital para tradução de autores brasileiros. Acesso em 06 ago. 2015. Disponível em: 
$<$ http://www.cultura.gov.br/noticias-destaques/-/asset publisher/OiKX3xIR9iTn/ content/id/1270586>.

OLIVEIRA, N. de. Verdades provisórias: anseios crípticos. São Paulo: Escrituras, 2004.

PORTAL BRASIL. 28 jul 2014. Governo lança na Flip programas para internacionalizar literatura brasileira. Acesso em 6 ago. 2015. Disponível em: $<$ http://www.brasil.gov.br/cultura/2012/07/governo-lanca-na-flip-programaspara-internacionalizar-literatura-brasileira> .

PROGRAMA DE APOIO À TRADUÇÃO E À PUBLICAÇÃO DE AUTORES BRASILEIROS NO EXTERIOR. Brazil: Literature Translation Grant. Centro de cooperação e difusão Fundação Biblioteca Nacional. 11 set. 2012. Ministério da cultura investirá US\$35 milhões na internacionalização da literatura brasileira até 2020. Disponível em: < http://bookcenterbrazil.wordpress.com/2012/09/11/inegestas-mauris-et-erat-sed/>. Acesso em 06 ago. 2015.

VENUTI, L. The translator's invisibility: a history of translation. London/New York: Routledge, 1995.

. Os escândalos da tradução. Trad. Laureano Pelegrin, Lucinéia Villela, Marileide Esqueda e Valéria Biondo. Bauru: EDUSC, 2002.

Lilia Baranski Feres LiliaBaranski@hotmail.com

Valéria Silveira Brisolara ValeriaBrisolara@yahoo.com

Recebido em: 27/9/2017

Aceito em: 18/2/2018

Publicado em Abril de 2018 